\title{
A New Approach for Reaching the Customer of the Digital Age: Cross-Device Advertising
}

\author{
R.Gülay Öztürk \\ Istanbul Commerce University, Istanbul, Turkey
}

\begin{abstract}
One of the most significant advantages of the digital era is the fact that it presents a wide array of choices, without any time or place restrictions, to the target audience of the past who obtains information from the relatively passive and restricted sources. The role of the mobile devices that people carry with them almost everywhere and the Internet is undeniable in determining the speed of access to the information among these many choices. For brands, it is getting more and more difficult to reach users who spend their days and hours in front of different screens and consume information very quickly. Cross-device advertising, which has become one of the important subjects of the digital advertising studies in 2014, has established itself as an important method for reaching out to the customers of the digital age who use multiple devises. In this context, this study aims to discuss the essentials of a new advertising method called cross-device advertising. It is an advertising method utilized in digital platform by brands that would like to deliver their messages through the right ads, at the right place and time to the users who have multiple device options in today's world.
\end{abstract}

Keywords: digitalization, digital advertising, new customer, cross-device, cross-device advertising, new advertising approach

\section{Introduction}

The people of today's world spend most of their time online. Advertisers are aware of this tendency of the consumers and try to seize the opportunity that the online world offers for the ads they are going to make for their products or brands. Among the current popular advertisement opportunities and channels, re-targeting, video ads, mobile ads, and social media ads stand out (Taylor, 2013, p. 18). Given this context, it is useful to examine the consumers' usage tendencies of devices.

It has been claimed that the consumption of mobile devices has significantly increased both in Turkey and worldwide and in turn an important change has also been observed in the user behaviors. Today, almost everyone looks at his/her phone while watching television or use both devices at the same time (Eskalen, 2014a). It has also been recorded that $90 \%$ of today's customers become active users on one device, but end the process on another device. Therefore, it has become possible that the customers living in the world of multiple devices make the purchasing decision on one device and finalizes the purchase on a different device (Nazareth, 2015). However, it is getting more difficult for brands to deliver their advertisement messages to a user engaged with more than one device at the same time. It has been observed that the brands have started to use a new method called cross-device advertising to overcome this difficulty. At this juncture, this study will first

R.Gülay Öztürk, Associate Professor, Faculty of Communication, Advertising Department, Istanbul Commerce University. 
present a conceptual definition of cross-device advertising and then it will go on to discuss how this new advertising method operates, why it is important for brands and advertising world, and lastly what benefits and challenges it presents.

\section{Theoretical Framework}

\section{The Concept of Cross-Device Advertising}

Cross-device advertising is regarded as one of the key advances in the field of digital advertising in recent

years ${ }^{1}$. It is defined as an integrated advertising approach that enables advertisers to reach the same user from different devices such as smartphones, tablets, and computers (Eskalen, 2014a). The ads in question provide the advertisers with the opportunity of making targeted advertising in every digital device and at the same time offer the chance to identify the prospective customers in these fields. However, it draws one's attention that the increase in the usage of mobile devices alters the way people obtain information about the products and their purchasing behaviors ${ }^{2}$. In a different research, it has been expressed that the users' device preferences could vary even at different hours of the same day. For example, smartphones are the last device that are used before going to sleep at nights; the most frequently used device between the hours 8.00-16.00 is computers and people tend to use their tablets more often after 19.00. Considering that watching TV series is a fairly significant practice in Turkey, the fact that there is a tendency for watching TV series on tablet is important for revealing that the tablet is a significant alternative for TV (Eskalen, 2014a). A research conducted in USA has shown that people may switch devise 21 times in an hour. This finding proves the importance of this advertising method. Therefore, the journey of cross-device makes the customer more active and the tracking of customers a requirement ${ }^{3}$. One of the issues worthy of attention is the expression of different purchasing intentions on different devices. According to this, the same display ad may not show the same impact across different devices. This situation requires advertisers to track the devices that the consumers use and which ads have an impact on them and to what degree. Two approaches are put forward in this direction. The first way to identify a customer across the devices $\mathrm{s} /$ he uses is the deterministic approach. This approach simply provides detailed information about customers connecting to a device through a $\log$ in system. The information is gathered from individuals' e-mail accounts, social media accounts, and bank accounts and considered to have $95 \%$ degree of accuracy. The second way to identify customers is probabilistic matching. In this approach, an algorithm is used to determine a match cross-device. It is stated that the algorithm follows people throughout the day and the information gathered in this way has a $60-90 \%$ degree of accuracy ${ }^{4}$. Therefore, one can see that all these approaches are important in determining which devices the customers use. In media planning, reaching the right target audience through the right medium, at the right time and place is considered an important criterion. In this context, it could be stated that cross-device advertising provides a significant competitive advantage to the brands. According to the findings of a study that has been conducted with 500 agencies, $84 \%$ of the marketers and $92 \%$ of the advertising agencies would like to use cross-device advertising; and 55\% of marketers and $66 \%$ of the agencies would like to increase their allotted budget for this type of advertising (Eskalen, 2014a). These findings are important for demonstrating the approach of the sector to cross-device advertising.

\footnotetext{
${ }^{1}$ Retrieved from http://www.spherelondon.co.uk, 2015.

2 Retrieved from http://www.spherelondon.co.uk, 2015.

${ }^{3}$ Retrieved from http://www.spherelondon.co.uk, 2015.

${ }^{4}$ Retrieved from http://www.spherelondon.co.uk, 2015.
} 
However, it is required to state that cross-device advertising is not a method that is as frequently used as desired yet and there are not many sources in the field of digital advertising in the literature. Depending on the current developments and the changes in the users' engagement with digital devices, it is apparent that cross-device advertising will provide a significant advantage to the brands in the upcoming years. In this context, it would be pertinent to examine this new concept of digital advertising literature in a detailed manner.

\section{The Operating System of Cross-Device Advertising}

Customers generally show the tendency of checking a brand's websites, applications, retail stores and ads. However, the information with regard to which device or devices they use for this type of browsing is of significance for the brand. Herein, it is observed that cross-device strategy provides remarkable benefits to marketers to optimize their customer and advertising expectations. However, it has been pointed out that marketers find cross-device advertising complicated. Primarily, some marketers lack competence across marketing platforms and from a planning perspective the campaigns are not actualized effectively. The deficiencies in tracking and analytics also impede the success of advertising. Besides, the probability that a person seeing an ad on a tablet one day and then purchasing the advertised product from the computer the next day leads to criticism regarding the success of cross-device strategy (Ad Age, n.d., p. 2). It is therefore significant to understand correctly how cross-device advertising operates.

The general outline of the operation is as follows: A brand, whose website is accessed on computer, identifies the user without accessing his/her user information. When the same user connects to Internet via smartphone or tablet, an ad about the brand could be shown to him/her. In this way, the message of the brand is directly delivered to the right target audience through the right medium (Eskalen, 2014a). Hence, making an exact match first is a generally suggested method. It is required that one uses lasting identifiers, establishes values, and secures the personal information. In the second step, implied matching should be performed. The machine learning model uses device characteristics to predict the probability that the same person uses two different devices at the same time. This situation, by definition, may lead to inaccurately matching two people. The degree of accuracy of this matching is $40-75 \%$, it could therefore considerably decrease performance and returns. Furthermore, the management of opt-out is claimed to be challenging (Ad Age, n.d., p. 7). Exact match is the combination of cross-device users and the private information about them. The current exact user match examples use more traditional methods such as credit card numbers, store loyalty cards, e-mail addresses, mobile phone numbers and home addresses. This method is highly suggested; however, it can't be used for all the consumers and platforms. Another alternative to exact match is implied match. It has a lower degree of accuracy and uses a "best guess" approach. It also cares about privacy concerns. Facebook, Yahoo, Google's Gmail and applications that require a single sign-on are some of the more popular platforms and methods. They are examples of exact match (Ad Age, n.d., p. 8). However, implied match may present certain problems. For example, the last user may not be the same in every platform or device. Individuals from the same family may use the same IP address on iPad. The information about the person who has the IP address will not be the same with the information regarding different people using this address leading thus to incorrect information about them. Besides, the fact that implied match raises privacy concerns is regarded as the biggest disadvantage of this method (Ad Age, n.d., p. 9). The following criteria should be taken into consideration to achieve good cross-device advertising:

- Measure and document how consumers consume your ads and content. 
- Integrate your cross-device targeting to your multichannel strategy.

- Determine your goals to decide which measurement strategy will yield the best results.

- Find the right partner to help you make the right match.

- Be transparent about the data you will collect and leave room for your costumer to opt out.

- Before embarking on this method of advertising, include design as well.

- Invest your money in a good talent (Ad Age, n.d., pp. 10-11).

All in all, the advances in the field of digital technology present the opportunity of re-targeting on different devices that belong to the same user. In this way, the brand is able to reach the users on the right device regardless of which medium the users choose to be in. However, one needs to wary of correct match and privacy of the user information in the execution of cross-device advertising.

\section{The Growing Importance of Cross-Device Advertising and Its Benefits}

The integrated technology provides today's brands with the opportunity of tracking the behaviors of customers using multi-devices (Spice, 2014, p. 1). When the mobile devices have established their dominance over desktop devices in 2013, the customers have started to spare more time to greater number of devices. This media fragmentation has been stated to cause a transition from a "nice-to-have" understanding to a "need-to-have". It also led to the emergence of a new concept called cross-device advertising (eMarketer, 2014, p. 1).

The advances in the field of technology have also altered the customers' shopping behaviors. For example, Forrester Research claims that the revenues from the web customers will be $\$ 1.8$ trillion by 2017 . This finding aptly demonstrates the reason why the online shopping behaviors should be taken into account. It has been recorded that $97 \%$ of the customers worldwide shop on computers; however, the extent of shopping on cross-devices has expanded. This suggests that more than 4 people in 10 shop on their smartphones and 4 of them shop on their tablets (Ad Age, n.d., p. 3). On the other hand, Constant Contact has surveyed small businesses and non-profit organizations in March 2014. The findings put forth that there has been $73 \%$ increase in customer engagement, $57 \%$ increase in acquiring new customers and $54 \%$ increase in website traffic due to multi-channel marketing activities (eMarketer, 2014, p. 1). It is apparent that marketing communications efforts on multichannel media present relatively significant results.

One of the examples that can illustrate the benefit that cross-device advertising provides for brands is Atlas application, a system dependent on Facebook and bought from Microsoft in 2014 rendering service on different devices (Eskalen, 2014a). The purpose of Atlas, which is fed by the Facebook identities of the users rather than cookies (Parmaksiz, 2015), is to show publishers how much website ads direct consumers to offline and online purchasing. If a person uses a phone, tablet or a desktop computer, this application could identify the person as the same user and is connected directly to his/her Facebook account. Hence, it is explained as an integrated advertisement effort that enables advertisers to reach the same user across different digital devices (smartphone, tablet, PC). It is claimed that Facebook's Atlas platform will yield better results in terms of advertising across devices (Eskalen, 2014a). However, there are some firms that are not as lucky as Facebook or Google. Firms such as Drawbridge and Tapad provide cross-device advertising service to these firms with an allegedly $70 \%$ degree of accuracy. This example is important since it shows that firms try to meet the demands in this field (Parmaksiz, 2015).

According to GWI Turkey Market Research Report, Turkey is more active in terms of multiscreen usage and media consumption compared to the global average. The consumption of second screen while consuming 
mobile is also above the average. We can say that customers also consume other devices while watching TV. Therefore, having ads on more than one device at the same time (mobile, tablet) becomes a requirement in Turkey as well. At this point, cross-device reports are needed ${ }^{5}$. Thanks to cross-device reports, the brands will be able to identify the devices on which people see their ads before transforming their applications or websites. For example, when you see the ad of a product on your mobile phone and decide to purchase it from your computer later, this transition will be captured by the cross-device report ${ }^{6}$. It could be stated that this data will present a significant advantage to brands.

\section{The Challenges of Cross-Device Advertising}

In addition to its benefits, the cross-device advertising also bring along certain challenges. Among these challenges, the first one concerns the correct analysis of the browsing behavior of the users across devices. Another challenge is to measure the attribution of investments and their returns. For example, the majority of customers see the ad on desktop; however it is not precisely known whether they purchase this advertised product on mobile devices later. According to the results of a research conducted by Criteo and its partner Digiday, there are three major reasons restricting cross-device advertising: Majority of the advertising and brand agencies are of the opinion that the degree of attribution is poor, there is no unified view of consumers across devices and there is low conversion rate in the mobile ads. Additionally, the issue of customers' privacy is also a growing concern (Ad Age, n.d., p. 4). Individuals particularly fear that others will obtain their private information. This growing fear in turn lead them to distance themselves from virtual platforms or exhibit a tendency not to divulge a lot of information about themselves. The active user of today's world would like to know who have access to their private information and how this information is stored, sold and used. Transparency in this area is stated to be rather low ${ }^{7}$. Another disadvantage of cross-device advertising is the difficulty of identifying and connecting with the users having the power to pass on to another device quickly for marketers (Buss, 2015). However, the concern regarding private information is viewed as a general problem across Internet; corporations are able to reach today's consumers, who lead a hectic life, effectively through cross-device targeting. It is claimed that advertisers are more likely to increase their revenue with this method ${ }^{8}$.

\section{Conclusion}

Digital media has, on the one hand, presented a wide set of data about users, and on the other hand has created a considerable impact in the rewriting of advertising principles by way of creative media. It has also provided the advertisers with the opportunity for significant and quick feedback through characteristics such as interactivity, personalization, and measurement (McStay, 2010, p. 1). The impact of digitalization on advertising and the advances in the field of digital advertising are considered to endow advertisers with the ability to track both online customers and advertising communities (McStay, 2010, p. 2). Accepted as one of the most effective communication methods (Özgüven, 2013, p. 7), mobile communication has made it possible to address a more active user profile without any time or place restraints and taken on a central role in the usage of multimedia. These merits of mobile communication have caught the attention of experts in the sector.

\footnotetext{
${ }^{5}$ Retrieved from http://docplayer.biz.tr, 2015.

${ }_{7}^{6}$ Retrieved from http://www.facebook.com, 2015.

7 Retrieved from http://www.spherelondon.co.uk, 2015.

8 Retrieved from http://www,spherelondon.co.uk, 2015.
} 
Advertising as a mass media faces certain challenges due to digital revolution. It is because the current ads on digital platforms are distinct from the traditional ads in terms of both content and form. One of the most prominent issues of today's advertising world is the fact that customers now have an unlimited realm of freedom in terms of using devices particularly with the onset of digital revolution through personal computers and mobile internet (Dyck, 2014, p. 14). The new generation has grown in an online world and learned to be interactive besides being listeners thanks to the opportunities that the digital presents. Considering that the brands are also aware of this fact, it has now become easier to understand why brands are attributing more and more significance to digital advertising applications (Açıkel \& Çelikol, 2014, p. 25).

Considering the fact that advertising only works when it reaches to its target audience (Dyck, 2014, p. 31), the types of digital advertisement are gradually increasing and brands are looking for efficient ways to deliver their advertisement messages by way of new and innovative applications in parallel with the increase in the multimedia usage in today's world.

One of these new methods is cross-device advertising. It is underlined that the increase in cross-device competency will be one of the most significant trends of 2015 in advertising sector and mobile technology will take on a central role in this field ${ }^{9}$. It is stated that this new method will enable advertisers to actualize purchases not based on channel or website, but based on the target audience. This will in turn present them a significant competitive advantage in reaching the right audience, at the right time and place and in re-targeting them by way of right devices and in becoming closer to them (MEC Diginews, 2015, p. 3).

Therefore, the main goal here is to achieve to talk to the right user at the right time. Cross-device advertising, in this context, is of key importance. The advertisers should always keep in mind that cross-device advertising present the possibility of solving problems through accurate match and they should be aware that "privacy of user data and not causing them any disturbance" are sensitive issues.

In conclusion, even though the world is becoming more and more complex everyday, it is possible to assert that methods such as cross-device advertising are able to deliver the brands' messages without disturbing the consumers through a content that is tailored for their interests and needs and through the appropriate devices for them.

\section{References}

“What does mean a cross-device reporting?". (n.d.). Retrieved from https://www.facebook.com/help/266118906912295.

"What is waiting to an e-commerce industry in 2015?". (2015). Retrieved from http://www.marketingturkiye.com.tr/content/2015te-e-ticaret sekt $\% \mathrm{C} 3 \% \mathrm{~B} 6 \mathrm{r} \% \mathrm{C} 3 \% \mathrm{BCn} \% \mathrm{C} 3 \% \mathrm{BC}$-neler-bekliyor Açıkel, E., \& Çelikol, M. (2014). Digitology (2nd ed.). İstanbul: MediaCat Kitapları.

Ad age, cross-device advertising: How to mobile marketing's next big opportunites. (n.d.). Retrieved from http://www.criteo.com/media/1036/cross-device-advertising-criteo-sep-2014.pdf

Buss, J. (2015). Confused about cross-device advertising? Here's what you need to know. Retrieved from http://www.huffingtonpost.co.uk/jon-buss/confused-about-crossdevice-advertising_b_6924662.html

Dyck, F. V. (2014). New generation advertising: New rules for digital age. İstanbul: The Kitap.

eMarketer. (2014). Cross-device trends Roundup. $\quad$ Retrieved from https://www.emarketer.com/public_media/docs/eMarketer_Cross_Device_Trends_Roundup.pdf

Eskalen, S. (2014a). Cross-Device Reklamcllik (Cross-device advertising). Retrieved from http://www.serkaneskalen.com/cross-device-reklamcilik/

\footnotetext{
${ }^{9} \mathrm{http} / / /$ www.marketingturkiye.com.tr, 2015.
} 
Eskalen, S. (2014b). Biliniyor ki Google sunduğu reklam formatlart ile fazlastyla kendisine kredi topluyor (It is known that more than collect his credit with advertising formats offered by Google). Retrieved from http://blog.turkcell.com.tr/facebook-atlas/ Invasive vs innovative-A look into cross-device advertising. (2015). Retrieved from http://www.spherelondon.co.uk/blog/invasive-vs-innovative--a-look-into-cross-device-advertising

McStay, A. (2010). Digital advertising. New York: Palgrave Macmillian.

MEC Diginews 2015. (2015). Retrieved from http://mecglobal.com.tr/assets/NewFolder/MEC-DIGINEWS-2015TR-3.pdf

Nazareth, G. (2015). Why should you pay attention to cross-device conversions?. Retrieved from $\mathrm{http} / /$ www.marketing-mojo.com/blog/why-should-you-pay-attention-to-cross-device-conversions/

Özgüven, N. (2013). Mobil Pazarlama ve Mobil Reklam (Mobile marketing and mobile advertising). Bursa: Dora Yayınc1lı.

Parmaksız, H. (2015). Endüstrinin Yeni Göz Bebeği: Çapraz Cihaz Hedefleme (A new cherry of one's cheek of industry: Cross-device targeting). Retrieved from http://www.uncdigital.com/endustrinin-yeni-goz-bebegi-capraz-cihaz-hedefleme/

Reach to masses between different screens. (n.d.). Retrieved from http://docplayer.biz.tr/2388449-Farkli-ekranlar-arasinda-kitlelere-ulasma.html

$\begin{array}{lllllll}\text { Spice, } & \text { R. (2014). } & \text { iCrossing } & \text { Pov: } & \text { Cros-device attribution. } & \text { Retrieved }\end{array}$ http://www.icrossing.com/sites/default/files/insight_pdf_files/CrossDevice\%20Attribution\%20-\%20iCrossing\%20POV\%20 $\% 20-\% 20062015$.pdf

Taylor, G. (2013). Advertising in a digital age. USA: Global \& Digital Publishing. 